\title{
Impact of small diameter and low level of emission laser coronary atherectomy in patients with acute myocardial infarction
}

\author{
Ryo Masuda ${ }^{1}$ (1) Takashi Shibui $^{2} \cdot$ Yoshiaki Mizunuma ${ }^{1} \cdot$ Shogo Yoshikawa $^{1} \cdot$ Kosuke Takeda $^{1} \cdot$ Hirofumi Kujiraoka ${ }^{1}$. \\ Koichiro Yamaoka ${ }^{1} \cdot$ Tomoyuki Arai $^{1} \cdot$ Dai Inagaki $^{1} \cdot$ Takashi Kimura $^{1} \cdot$ Kiyotaka Yoshida $^{1} \cdot$ Masao Takahashi $^{1}$. \\ Takeshi Kitamura ${ }^{1} \cdot$ Rintaro Hojo $^{1}$ - Takaaki Tsuchiyama ${ }^{1}$ - Seiji Fukamizu ${ }^{1} \cdot$ Tetsuo Sasano $^{3}$
}

Received: 24 May 2021 / Accepted: 18 August 2021 / Published online: 26 August 2021

(c) The Author(s) 2021

\begin{abstract}
Excimer laser coronary atherectomy (ELCA) is an effective treatment to remove intracoronary thrombi. In the present study, we compared in-hospital mortality in patients with acute myocardial infarction (AMI) who underwent conventional treatment and conventional treatment plus ELCA. Among 656 patients who were admitted to our hospital through the Tokyo CCU Network, 104 patients with AMI who were treated by percutaneous coronary intervention between January 2013 and December 2016 met inclusions criteria and underwent conventional treatment with ELCA (ELCA group) and 89 underwent conventional treatment alone (conventional group). We retrospectively evaluated in-hospital mortality within 30 days and used propensity score (PS) matching to reduce assignment bias and multivariate analysis to detect the predictors of in-hospital mortality. In-hospital mortality rate was significantly lower in the ELCA group before and after PS matching (2.9\% vs. 13.5\%, $p=0.006$ before PS matching, and $2.8 \%$ vs. $14.1 \%, p=0.016$ after PS matching). After PS matching, $\beta$-blocker or statins use, incidence of shock, Killip classification, and door-to-balloon time were not significantly different. A multivariate logistic regression analysis identified ELCA, dyslipidemia, shock, and left ventricular ejection fraction as independent predictors of in-hospital mortality (odds ratio (OR), 0.147, 95\% confidence interval [CI], 0.022-0.959, $p=0.045$; OR, 0.077, 95\% CI, 0.007-0.805, $p=0.032$; OR, 6.494, 95\% CI, 1.228-34.34, $p=0.028$; OR, 0.890, 95\% CI, 0.828-0.957, $p=0.002$, respectively). Our data indicate that ELCA with the small diameter and low level emission may reduce the in-hospital mortality compared to conventional methods in patients with AMI in drug-eluting stent era.
\end{abstract}

Keywords Laser coronary atherectomy $\cdot$ Acute myocardial infarction $\cdot$ In-hospital outcomes $\cdot$ Small diameter $\cdot$ Low level emission

\section{Introduction}

Acute myocardial infarction (AMI) is usually treated with drug-eluting stent (DES) implantation [1], although sometimes intracoronary thrombus is removed

Ryo Masuda

rm_ryomasuda@yahoo.co.jp

1 Department of Cardiology, Tokyo Metropolitan Hiroo Hospital, 2-34-10, Ebisu, Shibuya, Tokyo 150-0013, Japan

2 Department of Cardiology, Toshima Hospital in the Tokyo Metropolitan Health and Hospitals Corporation, 33-1, Sakaecho, Itabashi, Tokyo 173-0015, Japan

3 Department of Cardiology, Tokyo Medical and Dental University Hospital, 5-45, Yushima 1-Chome, Bunkyo, Tokyo 113-8519, Japan through manual aspiration to prevent distal emboli before stenting [2]. In the previous study, the utilization of manual aspiration catheters has demonstrated a positive impact on myocardial perfusion and late clinical outcome [3]. However, manual thrombus aspiration has limited efficacy in AMI with thrombus rich lesion. The main cause of procedural failure is insufficient thrombus removal. Another study was showing that it increases the risk of stroke [4]. Consequently, another capable technology for improved thrombus removal is highly needed [5]. ELCA is one of the most effective treatments to remove intracoronary thrombi [6]. Laser atherectomy in AMI presents several advantages: rapid elimination of the thrombus with vaporization, removal of procoagulant reactants, diminution of the risk of distal embolization, and reduction of platelet 
Fig. 1 Flow diagram of this study. The ELCA group received conventional treatment with ELCA, while the remaining patients were treated using conventional methods (conventional group). CPAOA, cardiopulmonary arrest on arrival; AMI, acute myocardial infarction; PCI, percutaneous coronary intervention; ELCA, excimer laser coronary atherectomy; TIMI, thrombolysis in myocardial infarction; STEMI, ST-elevation myocardial infarction

aggregation promotors ("stunned platelets" phenomenon) [7, 8]. Hence, the safety and capable thrombus removal technology of ELCA in patients with AMI was revived in recent few years especially in Japan [9]. In addition, ELCA has also been applied to a variety of difficult-to-treat lesions, including preparation before drug-coated balloon angioplasty [10]. ELCA improves thrombolysis in myocardial infarction (TIMI) frame count or myocardial blush grade (MBG) in patients with AMI [11-13]. However, clinical data supporting the utilization of ELCA in AMI remain scarce [14, 15]. This study aimed to compare in-hospital outcome in patients with AMI between conventional treatment and conventional treatment plus ELCA in the contemporary era of percutaneous coronary intervention (PCI).

\section{Methods}

\section{Study population}

Among 656 patients who were admitted to our hospital through the Tokyo CCU Network, 193 patients with AMI who underwent PCI between January 2013 and December 2016 were evaluated. AMI was diagnosed on the basis of universal definition of myocardial infarction [16]. AMI with cardiogenic shock was confirmed by clinical criteria. The clinical criteria were hypotension on admission (a systolic blood pressure of $<90 \mathrm{~mm} \mathrm{Hg}$ or the need for supportive catecholamines or mechanical supports to maintain a systolic blood pressure of $\geq 90 \mathrm{~mm} \mathrm{Hg}$ ). Patients with cardiopulmonary arrest on arrival were excluded. In this study, AMI included both ST segment elevation myocardial infarction
Fig. 2 Definition of PCI strategies in acute myocardial infarction. A Conventional methods and $\mathbf{B}$ our recent strategies with ELCA. ELCA, excimer laser coronary atherectomy; POBA, plain old balloon angioplasty

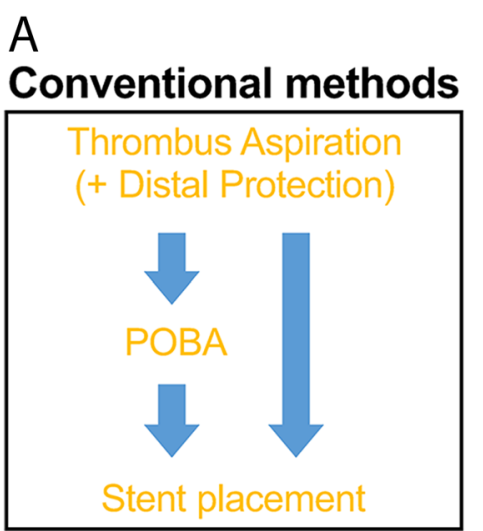

$B$

Our recent strategies with ELCA

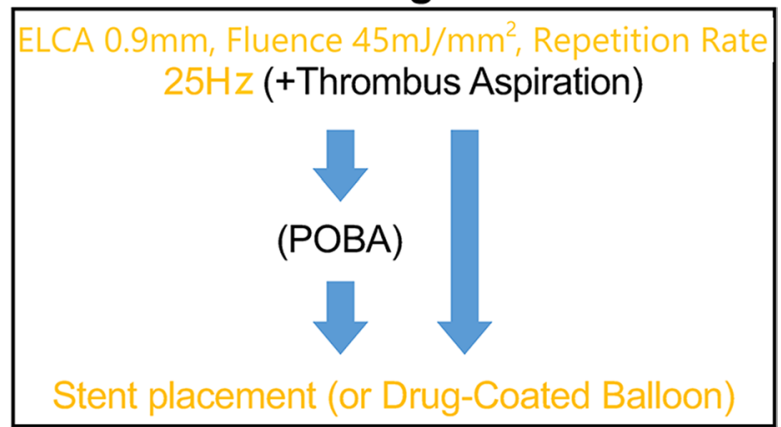


Table 1 Baseline clinical characteristic of patients

\begin{tabular}{|c|c|c|c|c|c|c|}
\hline & \multicolumn{3}{|c|}{ Before propensity score matching } & \multicolumn{3}{|c|}{ After propensity score matching } \\
\hline & Conventional & ELCA & $p$ value & Conventional & ELCA & $p$ value \\
\hline Variables & $(n=89)$ & $(n=104)$ & & $(n=71)$ & $(n=71)$ & \\
\hline Age years & $69.91 \pm 14.48$ & $67.35 \pm 13.77$ & 0.209 & $68.52 \pm 14.67$ & $67.9 \pm 14.17$ & 0.798 \\
\hline Sex category, male, $\%$ & $63(70.8)$ & $80(76.9)$ & 0.322 & $51(71.8)$ & $55(77.5)$ & 0.440 \\
\hline Smoker, $\%$ & $43(48.9)$ & $56(53.8)$ & 0.491 & $36(50.7)$ & $39(54.9)$ & 0.614 \\
\hline Diabetes, $\%$ & $28(31.5)$ & $27(26.0)$ & 0.399 & $24(33.8)$ & $20(28.2)$ & 0.468 \\
\hline Hypertension, \% & $56(62.9)$ & $55(52.9)$ & 0.160 & $46(64.8)$ & $39(54.9)$ & 0.231 \\
\hline Dyslipidemia, $\%$ & $41(46.1)$ & $51(49.0)$ & 0.680 & $34(47.9)$ & $36(50.7)$ & 0.737 \\
\hline Antiplatelets use, $\%$ & $24(27.0)$ & $24(23.1)$ & 0.533 & $20(28.2)$ & $15(21.1)$ & 0.330 \\
\hline Statins use, $\%$ & $23(25.8)$ & $22(21.2)$ & 0.443 & $18(25.4)$ & $13(18.3)$ & 0.310 \\
\hline ACEs / ARBs use, $\%$ & $29(32.6)$ & $25(24.0)$ & 0.187 & $23(32.4)$ & $18(25.4)$ & 0.355 \\
\hline$\beta$ blockers use, $\%$ & $13(14.6)$ & $15(14.4)$ & 0.971 & $12(16.9)$ & $9(12.7)$ & 0.478 \\
\hline STEMI, \% & $63(70.8)$ & $79(76.0)$ & 0.416 & $54(76.1)$ & $54(76.1)$ & 1.000 \\
\hline LVEF, \% & $49.7 \pm 13.23$ & $50.57 \pm 12.57$ & 0.632 & $48.8 \pm 13.3$ & $49.1 \pm 12.7$ & 0.904 \\
\hline Shock, $\%$ & $12(13.5)$ & $15(14.4)$ & 0.851 & $11(15.5)$ & $10(14.1)$ & 0.813 \\
\hline Door-to-balloon time, min & $676.51 \pm 173.21$ & $146.63 \pm 31.11$ & 0.003 & $147.92 \pm 15.5$ & $136.4 \pm 19.1$ & 0.640 \\
\hline Onset-to-door time, $\min$ & $448.86 \pm 571.81$ & $506.63 \pm 1119.03$ & 0.705 & $435.58 \pm 581.80$ & $523.75 \pm 1329.09$ & 0.652 \\
\hline \multicolumn{7}{|l|}{ MI location } \\
\hline Inferior, $\%$ & $36(40.4)$ & $37(35.6)$ & 0.318 & $28(39.4)$ & $24(33.8)$ & 0.208 \\
\hline Posterior, $\%$ & $6(6.7)$ & $8(7.7)$ & & $5(7.0)$ & $5(7.0)$ & \\
\hline Anterior, $\%$ & $43(48.3)$ & $47(45.2)$ & & $34(47.9)$ & $34(47.9)$ & \\
\hline Lateral, \% & $4(4.5)$ & $12(11.5)$ & & $4(5.6)$ & $8(11.3)$ & \\
\hline Troponin I $\mu \mathrm{g} / \mathrm{ml}$ & $32.83 \pm 10.6$ & $53.12 \pm 17.7$ & 0.346 & $37.58 \pm 13.1$ & $43.9 \pm 20.2$ & 0.792 \\
\hline \multicolumn{7}{|l|}{ KILLIP classification } \\
\hline I or II, $\%$ & $72(80.9)$ & $88(84.6)$ & 0.494 & $56(78.9)$ & $56(78.9)$ & 1.000 \\
\hline III or IV, \% & $17(19.1)$ & $16(15.4)$ & & $15(21.1)$ & $15(21.1)$ & \\
\hline \multicolumn{7}{|l|}{ Initial TIMI grade } \\
\hline $0, \%$ & $44(50.0)$ & $45(43.3)$ & 0.641 & $37(52.1)$ & $40(56.3)$ & 0.740 \\
\hline $1, \%$ & $7(8.0)$ & $6(5.8)$ & & $7(9.9)$ & $4(5.6)$ & \\
\hline $2, \%$ & $15(17.0)$ & $20(19.2)$ & & $11(15.5)$ & $9(12.7)$ & \\
\hline $3, \%$ & $22(25.0)$ & $33(31.7)$ & & $16(22.5)$ & $18(25.4)$ & \\
\hline \multicolumn{7}{|l|}{ Final TIMI grade } \\
\hline $0, \%$ & $2(2.2)$ & $0(0.0)$ & 0.311 & $2(2.8)$ & $0(0.0)$ & 0.328 \\
\hline $1, \%$ & $1(1.1)$ & $1(1.0)$ & & $1(1.4)$ & $1(1.4)$ & \\
\hline $2, \%$ & $1(1.1)$ & $0(0.0)$ & & $1(1.4)$ & $0(0.0)$ & \\
\hline $3, \%$ & $85(95.5)$ & $103(99.0)$ & & $67(94.4)$ & $70(96.5)$ & \\
\hline
\end{tabular}

Data are presented as $n(\%)$, except for age, left ventricular ejection fraction (LVEF), door-to-balloon time, onset-to-door time, and troponin I level, which are presented as mean \pm standard deviation. ARBs angiotensin II receptor blockers; ACEs angiotensin converting enzyme inhibitors; STEMI ST-elevation myocardial infarction; $M I$ myocardial infarction; TIMI thrombolysis in myocardial infarction; ELCA excimer laser coronary atherectomy

(STEMI) and non-ST segment elevation myocardial infarction (NSTEMI). The reasons are as follows. First, in a study to examine the relationship between the thrombectomy effect of ELCA and outcome, it was considered that there was no need to separate them because they were the same occurring mechanism due to thrombus associated with plaque rupture or erosion. However, unstable angina without elevation of cardiac troponin was excluded because it may have a favorable prognosis. Second, STEMI is difficult to analyze because of the small number of cases. Third, the earlier CARMEL multicenter registry did not separate the two [14]. A total of 104 patients underwent conventional treatment with ELCA (ELCA group) and 89 underwent conventional methods (conventional group) (Fig. 1). The timing of PCI was decided according to the AHA/ACC guidelines [17, 18]. Six patients with NSTEMI (4 patients 


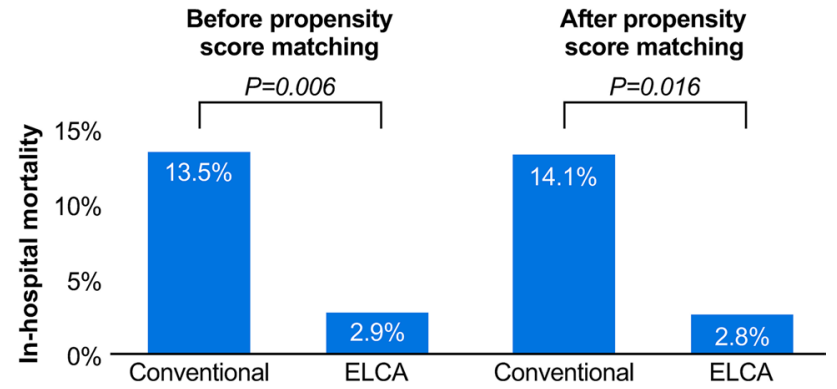

Fig. 3 In-hospital mortality within 30 days in patients suffering AMI. In-hospital mortality rate in percent within 30 days in patients suffering acute myocardial infarction (AMI) treated by conventional methods or conventional methods and excimer laser coronary atherectomy (ELCA) before and after propensity score matching

in the conventional group, 2 patients in the ELCA group) were undergoing PCI within 25 to $72 \mathrm{~h}$ of admission, and have pending improvement of pulmonary congestion due to heart failure. And all the other patients were undergoing PCI within $24 \mathrm{~h}$. Propensity score (PS) matching was used to reduce treatment assignment bias. After PS matching, 71 patients in the conventional group and 71 in the ELCA group were evaluated. Conventional methods were defined as standard PCIs, including thrombus aspiration and distal protection (Fig. 2A). All ELCA procedures were performed using the Spectranetics apparatus (CVX-300 platform, Spectranetics, Colorado Springs, CO, USA). It is composed of a generator of excimer laser (CVX-300) and pulsed xenonchloride laser catheters able to deliver laser emission from 45 to $60 \mathrm{~mJ} / \mathrm{mm}^{2}$ (fluence) at pulse repetition rates of 25 to
$40 \mathrm{~Hz}$. The operators determined the excimer laser catheters which size was suitable concentric 0.9 or $1.4 \mathrm{~mm}$ judging from the result of the angiographic and intracoronary imaging. Based on our previous study, we have a tendency to use the smaller 0.9-mm excimer laser catheter (Fig. 2B) [13].

\section{Outcomes}

We retrospectively compared in-hospital mortality within 30 days between the two groups. Furthermore, we determined the predictors of in-hospital mortality within 30 days using PS matching.

\section{Statistical analysis}

Categorical data are expressed as percent with the number of samples in parentheses. Continuous data are expressed as mean \pm standard deviation (SD). Categorical data were analyzed using the chi-squared test or Fisher's exact test. Between-group comparison of the continuous data was performed using the unpaired $t$ test. All tests were two-sided and considered significant when $p$ value was inferior to 0.05 . Covariates of PS calculation used age, ST-elevation myocardial infarction, shock, Killip classification [19], initial TIMI grade [20], and door-to-balloon time. We used multivariate logistic regression analysis to estimate the predictors of inhospital mortality. All statistical analyses were performed using the 17th version of the software SPSS (IBM SPSS Statistics, IBM, Armonk, NY, USA).
Table 2 Predictors of in-hospital mortality identified by univariate and multivariate logistic regression analyses, before propensity score matching

\begin{tabular}{|c|c|c|c|c|c|c|}
\hline & \multicolumn{3}{|c|}{ Univariate analysis } & \multicolumn{3}{|c|}{ Multivariate analysis } \\
\hline & OR & $95 \%$ CI & $p$ value & OR & $95 \% \mathrm{CI}$ & $p$ value \\
\hline Age & 1.052 & $1.006-1.101$ & 0.026 & 1.068 & $1.009-1.131$ & 0.024 \\
\hline Sex category, male & 0.364 & $0.125-1.062$ & 0.064 & & & \\
\hline Current smoker & 0.314 & $0.096-1.023$ & 0.055 & & & \\
\hline Diabetes & 1.280 & $0.417-3.932$ & 0.666 & & & \\
\hline Hypertension & 0.722 & $0.232-2.250$ & 0.574 & & & \\
\hline Dyslipidemia & 0.250 & $0.068-0.916$ & 0.036 & & & \\
\hline Statins use (pre-PCI) & 1.215 & $0.367-4.020$ & 0.750 & & & \\
\hline ACEs/ARBs use (pre-PCI) & 0.931 & $0.283-3.060$ & 0.906 & & & \\
\hline Anterior MI & 0.746 & $0.255-2.184$ & 0.593 & & & \\
\hline LVEF & 0.909 & $0.866-0.954$ & $<0.001$ & 0.915 & $0.866-0.968$ & 0.012 \\
\hline Cardiogenic shock & 9.564 & $3.119-29.324$ & $<0.001$ & 12.261 & $1.693-88.821$ & 0.013 \\
\hline Door-to-balloon time & 1.000 & $1.000-1.000$ & 0.599 & & & \\
\hline Cardiac troponin I & 1.002 & $1.000-1.004$ & 0.119 & & & \\
\hline KILLIP classification $(>==\mathrm{III})$ & 9.625 & $3.144-29.469$ & $<0.001$ & 7.635 & $1.376-42.373$ & 0.020 \\
\hline Initial TIMI grade & 0.674 & $0.424-1.071$ & 0.095 & & & \\
\hline Final TIMI grade & 0.539 & $0.227-1.278$ & 0.161 & & & \\
\hline ELCA & 0.191 & $0.052-0.699$ & 0.012 & 0.176 & $0.039-0.792$ & 0.024 \\
\hline
\end{tabular}



in-hospital mortality identified by univariate and multivariate logistic regression analyses, after propensity score matching
Table 3 Predictors of

\begin{tabular}{|c|c|c|c|c|c|c|}
\hline & \multicolumn{3}{|c|}{ Univariate analysis } & \multicolumn{3}{|c|}{ Multivariate analysis } \\
\hline & OR & $95 \% \mathrm{CI}$ & $p$ value & OR & $95 \% \mathrm{CI}$ & $p$ value \\
\hline Age & 1.039 & $0.991-1.089$ & 0.110 & & & \\
\hline Sex category, male & 0.653 & $0.184-2.313$ & 0.509 & & & \\
\hline Current smoker & 0.269 & $0.069-1.037$ & 0.057 & & & \\
\hline Diabetes & 1.125 & $0.320-3.953$ & 0.854 & & & \\
\hline Hypertension & 0.446 & $0.134-1.483$ & 0.188 & & & \\
\hline Dyslipidemia & 0.080 & $0.010-0.641$ & 0.017 & 0.077 & $0.007-0.805$ & 0.032 \\
\hline Statins use (pre-PCI) & 1.214 & $0.308-4.788$ & 0.781 & & & \\
\hline ACEs/ARBs use (pre-PCI) & 0.467 & $0.098-2.229$ & 0.339 & & & \\
\hline Anterior MI & 0.760 & $0.229-2.517$ & 0.653 & & & \\
\hline LVEF & 0.888 & $0.835-0.943$ & $<0.001$ & 0.890 & $0.828-0.957$ & 0.002 \\
\hline Cardiogenic shock & 11.600 & $3.243-41.496$ & $<0.001$ & 6.494 & $1.228-34.34$ & 0.028 \\
\hline Door-to-balloon time & 0.999 & $0.994-10 . .4$ & 0.622 & & & \\
\hline Cardiac troponin I & 1.002 & $1.000-1.005$ & 0.074 & & & \\
\hline KILLIP classification $(>==\mathrm{III})$ & 9.818 & $2.717-35.483$ & $<0.001$ & & & \\
\hline Initial TIMI grade & 0.733 & $0.430-1.250$ & 0.255 & & & \\
\hline Final TIMI grade & 0.555 & $0.232-1.326$ & 0.185 & & & \\
\hline ELCA & 0.177 & $0.037-0.839$ & 0.029 & 0.147 & $0.022-0.959$ & 0.045 \\
\hline
\end{tabular}

The odds ratio (OR) and 95\% confidence interval (CI) are shown. Categories with a significant difference based on the univariate analysis were used as covariates for multivariate analysis. ARBs angiotensin II receptor blockers; ACEs angiotensin converting enzyme inhibitors; $M I$ myocardial infarction; $L V E F$ left ventricular ejection fraction; TIMI thrombolysis in myocardial infarction; ELCA excimer laser coronary atherectomy

Ethical approval/informed consent This study was conducted in accordance with the principles of the Declaration of Helsinki and in compliance with the International Conference on Harmonization-Good Clinical Practice and local regulatory requirements. The study was approved by the Tokyo Metropolitan Hiroo Hospital ethics committee. All patients provided written informed consent to receive ELCA treatment and have their data used this study.

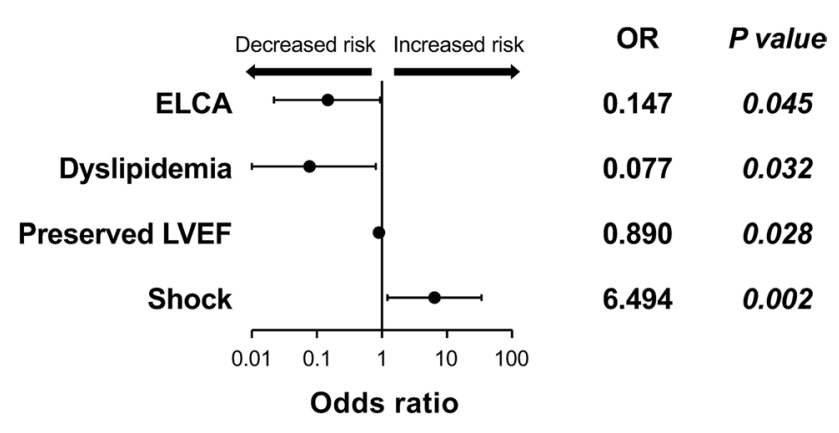

Fig. 4 Forest plot representing the odds ratios for risk of in-hospital mortality. Forest plot showing odds ratios (ORs) for significant predictors of in-hospital mortality that were identified by multivariate logistic regression analysis. ELCA, excimer laser coronary atherectomy; LVEF, left ventricular ejection fraction

\section{Results}

Table 1 shows baseline clinical characteristics of the two groups. After PS matching, we detected no significant differences between the two groups concerning $\beta$ blockers or statins use, incidence of shock, Killip classification, symptom onset-to-door time, and door-to-balloon time (Table 1). The mean laser catheter diameter, maximum fluence, and repetition rate were $1.08 \mathrm{~mm}, 51.1 \mathrm{~mJ} / \mathrm{mm}^{2}$, and $31.3 \mathrm{~Hz}$, respectively. In $10.9 \%$ of the cases, the fluence and repetition rate were increased due to poor improvement in coronary blood flow. In-hospital mortality rate (all mortality cases were cardiovascular deaths that were not caused by PCI procedures or ELCA-related devices) was significantly lower in the ELCA group than the conventional group before and after PS matching ( $2.9 \%$ vs. $13.5 \%, p=0.006$ before PS matching, and $2.8 \%$ vs. $14.1 \%, p=0.016$ after PS matching) (Fig. 3). A multivariate logistic regression analysis identified ELCA (odds ratio (OR), 0.147; 95\% confidence interval [CI], 0.022-0.959; $p=0.045$ ), dyslipidemia (OR, 0.077; 95\% CI, 0.007-0.805; $p=0.032$ ), left ventricular ejection fraction (OR, 0.890; 95\% CI, 0.828-0.957; $p=0.002)$, and shock (OR, 6.494; 95\% CI, 1.228-34.34; $p=0.028$ ) as independent predictors of in-hospital mortality (Tables 2 and 3 and Fig. 4). Moreover, ELCA reduced in-hospital mortality rate by $87 \%$ as analyzed using inverse PS weighting (OR, 0.227; 95\% CI, $0.060-0.863 ; p=0.030$ ). 
Table 4 Incremental cost-effectiveness ratio of ELCA in patients with AMI in Japan

\begin{tabular}{|c|c|c|}
\hline \multicolumn{2}{|l|}{ Devices } & Cost \\
\hline \multicolumn{2}{|l|}{ Aspiration catheter } & $¥ 40,800$ \\
\hline \multicolumn{2}{|l|}{ Filter wire set } & $¥ 119,000$ \\
\hline \multicolumn{2}{|l|}{ Total } & $¥ 159,800$ \\
\hline \multicolumn{2}{|l|}{ Laser catheter } & $¥ 211,000$ \\
\hline \multicolumn{2}{|l|}{ Incremental cost } & $¥ 51,200$ \\
\hline & Cost & Alive \\
\hline Conventional & $¥ 159,800 \times 71$ & 61 \\
\hline ELCA & $¥ 211,000 \times 71$ & 69 \\
\hline
\end{tabular}

Cost of devices and the number of patients who are alive were presented and used to calculate the incremental cost-effectiveness ratio (ICER) per lifesaving procedure in Japanese yen (¥) and USD. Cost in USD has been converted from cost in yen using the current exchange rate and should be interpreted with caution due to possible large price disparities between devices in Japan and other countries. Abbreviations: ELCA excimer laser coronary atherectomy

\section{Discussion}

In the present study, patients with AMI who underwent small diameter ELCA (i.e., $1.4 \mathrm{~mm}$ or less) and low level fluence (around $50 \mathrm{~mJ} / \mathrm{mm}^{2}$ ) had a significant reduction in in-hospital mortality rate of $2.9 \%$. The detailed mechanism is unknown because there is no significant difference in final TIMI flow. The efficiency of ELCA could be associated with its intrinsic properties. Indeed, excimer laser is a form of ultraviolet laser, which has been reported to remove or reduce atherosclerotic plaques and thrombi [21], improve microcirculation in patients with acute coronary syndrome (ACS) compared to thrombus aspiration therapy [22], and cause the "stunned platelets" phenomenon that reduce platelet aggregation [8]. Given that we previously identified a significant improvement in MBG induced by ELCA [13], an improvement in microcirculation is the most probable cause for the decrease in in-hospital mortality rate. In the previous study, it was reported that "platelet stunning" effect is dose dependent and most pronounced at high levels of laser emission such as $60 \mathrm{~mJ} / \mathrm{mm}^{2}$ [6]. However, approximately $10 \%$ of the cases experienced deterioration of the TIMI flow grade when the level gradually increased from a low level to a high level of laser emission. We believed that strong acoustic shock waves, rather than vaporization of thrombus, may cause distal emboli under high level irradiation; therefore, we have recently been using a low level of fluence such as $45-55 \mathrm{~mJ} / \mathrm{mm}^{2}$. Additionally, although the rate of in-hospital mortality in the conventional group in this study was $13.5 \%$, which is higher than that of other hospitals in Japan [23], there are contributing factors, such as the fact that transport by air from remote islands accounts for approximately
$40 \%$ of all ACS cases in our hospital and patients with severe shock requiring mechanical support have not been excluded in this study. Taking these into account, the $2.9 \%$ rate of in-hospital mortality in the ELCA group is staggering. Furthermore, our data may have been more effective for organized thrombi that were a little late in the onset of AMI. Finally, to change the subject, the laser catheter is expensive at 1210,000 yen (approximately 2,000 USD), but the incremental cost-effectiveness ratio (ICER) calculated in this study is 1454,400 (approximately 4,200 USD) per lifesaving procedure, which is an acceptable cost (Table 4).

\section{Conclusion}

Our data indicate that ELCA with small diameter and low level emission may reduce the in-hospital mortality rate than the conventional methods in patients with AMI. ELCA is feasible and cost-effective in patients with AMI.

Limitations This study included only a small number of participants and retrospective observational one in only single center. STEMI and NSTEMI should have been analyzed separately, but the number of participants was small and the analysis was quite difficult. ICER should be calculated based on the cost for 1 year instead of 1 month, but this time, we assumed that there would be no difference in the cost after 1 month of survival. Precisely, the medical insurance system in each country should be considered. Multicenter randomized controlled trials are warranted to confirm this observational study in the future.

Acknowledgements Editorial support, in the form of medical writing, assembling tables and creating high-resolution images based on authors' detailed directions, collating author comments, copyediting, fact checking, and referencing, was provided by Editage, Cactus Communications.

Author contribution Not applicable.

Data and materials availability Not applicable.

Code availability Not applicable.

\section{Declarations}

Ethics approval The study was approved by the Tokyo Metropolitan Hiroo Hospital ethics committee.

Consent to participate All patients provided written informed consent to receive the treatment and have their data used this study.

Consent for publication Not applicable. 
Conflict of interest The authors declare no competing interests.

Open Access This article is licensed under a Creative Commons Attribution 4.0 International License, which permits use, sharing, adaptation, distribution and reproduction in any medium or format, as long as you give appropriate credit to the original author(s) and the source, provide a link to the Creative Commons licence, and indicate if changes were made. The images or other third party material in this article are included in the article's Creative Commons licence, unless indicated otherwise in a credit line to the material. If material is not included in the article's Creative Commons licence and your intended use is not permitted by statutory regulation or exceeds the permitted use, you will need to obtain permission directly from the copyright holder. To view a copy of this licence, visit http://creativecommons.org/licenses/by/4.0/.

\section{References}

1. Anderson JL, Morrow DA (2017) Acute myocardial infarction. N Engl J Med 376:2053-2064

2. Ozaki Y, Katagiri Y, Onuma Y, Amano T, Muramatsu T, Kozuma K, Otsuji S, Ueno T, Shiode N, Kawai K et al (2018) CVIT expert consensus document on primary percutaneous coronary intervention (PCI) for acute myocardial infarction (AMI) in 2018. Cardiovasc Interv Ther 33:178-203

3. Vlaar PI, Svilaas T, van der Horst IC et al (2008) Cardiac death and reinfarction after 1 year in the Thrombus Aspiration during Percutaneous coronary intervention in Acute myocardial infraction Study [TAPAS]: a 1 -year follow-up study. Lancet 371:1915-1920

4. Jolly SS, Cairns JA, Yusuf S, Meeks B, Pogue J, Rokoss MJ, Kedev S, Thabane L, Stankovic G, Moreno R, Gershlick A, Chowdhary S, Lavi S, Niemela K, Steg PG, Bernat I, Xu Y, Cantor WJ, Overgaard CB, Naber CK, Cheema AN, Welsh RC, Bertrand OF, Avezum A, Bhindi R, Pancholy S, Rao SV, Natarajan MK, Ten Berg JM, Shestakovska O, Gao P, Widimsky P, Dzavik $\mathrm{V}$ (2015) For the TOTAL Investigators. Randomized trial of primary PCI with or without routine manual thrombectomy. N Engl J Med 372:1389-1398

5. Topaz O, Perin EC, Jesse RL, Mohanty PK, Carr ME Jr, Rosenschein U (2003) Power thrombectomy in acute coronary syndrome. Angiology 54:457-468

6. Topaz O (2018) Cardiovascular Thrombus: from pathology and clinical presentations to imaging, pharmacotherapy and interventions. Elsevier-AP, London, pp 267-283

7. Karacsonyi J, Armstrong EJ, Truong HTD, Tsuda R, Kokkinidis DG, Martinez-Parachini JR, Alame AJ, Danek BA, Karatasakis A, Roesle M et al (2018) Contemporary use of laser during percutaneous coronary interventions: insights from the Laser Veterans Affairs (LAVA) Multicenter Registry. J Invasive Cardiol 30:195-201

8. Topaz O, Minisi AJ, Bernardo NL, McPherson RA, Martin E, Carr SL, Carr ME (2001) Alterations of platelet aggregation kinetics with ultraviolet laser emission: the "stunned platelet" phenomenon. Thromb Haemost 86:1087-1093

9. Nishino M, Mori N, Takiuchi S, Shishikura D, Doi N, Kataoka T, Ishihara T, Kinoshita N (2017) ULTRAMAN Registry investigators. Indications and outcomes of excimer laser coronary atherectomy: efficacy and safety for thrombotic lesions - the ULTRAMAN registry. J Cardiol. 69:314-319
10. Shibui T, Tsuchiyama T, Masuda S, Nagamine S (2021) Excimer laser coronary atherectomy prior to paclitaxel-coated balloon angioplasty for de novo coronary artery lesions. Lasers Med Sci 36(1):111-117. https://doi.org/10.1007/s10103-020-03019-w

11. Dörr M, Vogelgesang D, Hummel A, Staudt A, Robinson DM, Felix SB, Dahm JB (2007) Excimer laser thrombus elimination for prevention of distal embolization and no-reflow in patients with acute ST elevation myocardial infarction: results from the randomized Laser AMI study. Int J Cardiol 116:20-26

12. Ambrosini V, Cioppa A, Salemme L, Tesorio T, Sorropago G, Popusoi G, Stabile E, Medolla A, Cangella F, Agrusta M et al (2008) Excimer laser in acute myocardial infarction: single centre experience on 66 patients. Int J Cardiol 127:98-102

13. Nagamine S, Ashikaga T, Masuda S, Komiyama K, Tsuchiyama T, Shibui T, Hirao K (2019) Comparison of 0.9-mm and 1.4-mm catheters in excimer laser coronary angioplasty for acute myocardial infarction. Lasers Med Sci 34:1747-1754

14 Topaz O, Ebersole D, Das T, Alderman EL, Madyoon H, Vora K, Baker JD, Hilton D, Dahm JB (2004) CARMEL multicenter trial. Excimer laser angioplasty in acute myocardial infarction (the CARMEL multicenter trial). Am J Cardiol 93:694-701

15. Rawlins J, Din JN, Talwar S, O'Kane P (2016) Coronary intervention with the excimer laser: review of the technology and outcome data. Interv Cardiol 11:27-32

16. Thygesen K, Alpert JS, Jaffe AS, Chaitman BR, Bax JJ, Morrow DA et al (2018) Fourth Universal Definition of Myocardial Infarction. J Am Coll Cardiol (2018) 72:2231-2264

17. Patrick O, Frederick K, Deborah A et al (2013) 2013 ACCF/AHA Guideline for the Management of ST-Elevation Myocardial Infarction. Circulation 127:e362-e425. https://doi.org/10.1161/CIR. 0b013e3182742cf6

18. Ezra A, Nanette W, Ralph B et al (2014) 2014 AHA/ACC guideline for the management of patients with non-ST-elevation acute coronary syndromes. Circulation 130:e344-e426. https://doi.org/ 10.1161/CIR.0000000000000134

19 Killip T, Kimball JT (1967) Treatment of myocardial infarction in a coronary care unit. A two year experience with 250 patients. Am J Cardiol 20:457-464

20 TIMI Study Group (1985) The thrombolysis in myocardial infarction (TIMI) trial. Phase I findings. N Engl J Med. 312:932-936

21. Topaz O, Bernardo NL, Shah R, McQueen RH, Desai P, Janin Y, Lansky AJ, Carr ME (2001) Effectiveness of excimer laser coronary angioplasty in acute myocardial infarction or in unstable angina pectoris. Am J Cardiol 87:849-855

22. Shishikura D, Otsuji S, Takiuchi S, Fukumoto A, Asano K, Ikushima M, Yasuda T, Hasegawa K, Kashiyama T, Yabuki M et al (2013) Vaporizing thrombus with excimer laser before coronary stenting improves myocardial reperfusion in acute coronary syndrome. Circ J 77:1445-1452

23. Yasuda S, Nakao K, Nishimura K, Miyamoto Y, Sumita Y, Shishido T, Anzai T, Tsutsui H, Ito H, Komuro I et al (2016) The current status of cardiovascular medicine in Japan - analysis of a large number of health records from a nationwide claim-based database. JROAD-DPC Circ J 80:2327-2335

Publisher's Note Springer Nature remains neutral with regard to jurisdictional claims in published maps and institutional affiliations. 